\title{
Role of Ghrelin Hormone in Systemic Lupus Erythematosus: Relation to Interferon alpha and Disease Activity Biomarkers
}

\author{
Amira F. Barakat ${ }^{1}$, Ehab E. Eltoraby ${ }^{1}$, Dina Shahin ${ }^{1}$, Adel I. Abdelsalam ${ }^{1}$, \\ Moustafa Abdelsalam ${ }^{1}$, Noha M. Shaat ${ }^{2}$, Ayman Z. Alsamanoudy ${ }^{3}$ \\ Departments of Internal Medicine ${ }^{1}$, Rheumatology \& Rehabilitation ${ }^{2}$, \\ Biochemistry ${ }^{3}$, Mansoura University; Egypt
}

\begin{abstract}
Background: SLE is an autoimmune multisystem disease which results from both genetic predisposition and environmental factors. Ghrelin polypeptide is the natural ligand for the growth hormone secretagogue receptor exerts multiple immune regulatory effects as well as cardiovascular, metabolic and renal effects. On the other hand it was reported that some patients who have received recombinant human INF- $\alpha$ injections to treat chronic viral infections or malignancy have developed de novo SLE which resolves with discontinuation of IFN- $\alpha$ therapy. Our study was conducted to evaluate levels of ghrelin and INF- $\alpha$ in SLE patients, their relation to different clinical manifestations of the disease and their correlation with disease activity markers in such patients. Methods: Fifty four SLE patients and 46 age and sex matched control healthy subjects were included in this study. Both ghrelin hormone and INF- $\alpha$ were measured for all the studied groups using enzyme linked immune sorbent assay (ELISA) kit. We compare serum levels between SLE patients and control subjects also serum levels were correlated to different clinical manifestations and disease activity markers. Results: In this study we found significant increase in ghrelin hormone level in patients with lupus nephritis $(\mathrm{p}=0,0004)$ also it positively correlated with SLEDAI $(\mathrm{p}<0.0001), \operatorname{INF} \alpha(\mathrm{r}=0.3 \& \mathrm{p}<0.01)$, ANA $(\mathrm{p}<0.0001)$, dsDNA $(\mathrm{p}<0.002)$ and LDL $(\mathrm{p}=0.03)$ but there was negative correlation between ghrelin and both body weight and HDL. On the other hand there was no significant change in ghrelin hormone level in SLE patients with mucocutaneous manifestations, articular involvement, Cerebritis, serositis, vasculitis and constitutional symptoms. Conclusion: These data suggest the possible role for ghrelin hormone in the clinical manifestation of SLE patients especially those with lupus nephritis as well as the synchronization of both ghrelin and INF $\alpha$ in the pathogenesis of SLE and their role in disease activity. [Egypt J Rheumatology \& Clinical Immunology, 2014; 2(1): 89-96]
\end{abstract}

Key Words: SLE, ghrelin, interferon alpha

\section{INTRODUCTION}

Systemic lupus erythematosus (SLE) is a severe multi-system autoimmune disease which results from both genetic predisposition and environmental factors. ${ }^{1}$ Ghrelin is a unique 28 amino acid peptide containing an n-octanoyl group on the serine in position 3 that was purified from rat stomach by Kojima et al. in $1999 .^{2}$ Ghrelin is the natural ligand for the growth hormone secretagogue (GHS) receptor (GHS-R) cloned in 1996 by Howard et al. ${ }^{3}$ Circulating ghrelin consists of more than $90 \%$ of desacyl ghrelin and less than $10 \%$ acyl ghrelin. ${ }^{4}$ In addition to the stomach, ghrelin is expressed in many tissues such as duodenum, jejunum, ileum, colon, lung, heart, pancreas, kidney, testis, pituitary, and hypothalamus. $^{5,6}$ Recent studies show that ghrelin produces a positive energy balance by stimulating food

Correspondence to Ehab Eltoraby, Department of Internal Medicine, Mansoura University; Egypt

e-mail ehabeltoraby@yahoo.com intake and decreasing fat utilization through its GHindependent mechanism. Besides its appetite stimulating effect, evidence has emerged that ghrelin exerts multiple immune-regulatory effects as well as affecting the cardiovascular system and renal function. One recent study evaluated ghrelin levels in pediatric patients with SLE. ${ }^{7}$ However; it has not clarified whether ghrelin levels in SLE are related to the inflammatory process in such patients. Other previous reports have focused on ghrelin role in cachexia of cardiovascular disease or chronic renal failure. $^{8,9}$

Interferon- $\alpha$ (INF- $\alpha)$ is an anti-viral cytokine in the type I INF family, which also includes INF- $\beta$, INF- $\varepsilon$, and INF- $\kappa$. Interferon alpha (IFN- $\alpha$ ) and interferon beta (IFN$\beta$ ), signal through the same type I interferon receptor, results in a wide range of effects upon the immune system. IFN- $\alpha$ normally functions in viral defense, and forms a bridge between the innate and adaptive immune systems. ${ }^{10}$ In this way, IFN- $\alpha$ is also important in setting thresholds for self reactivity and autoimmunity. It was reported that some patients who have received recombinant human IFN- $\alpha$ injections to treat chronic 
viral infections or malignancy have developed de novo SLE which resolves with discontinuation of IFN- $\alpha$ therapy. ${ }^{11,12}$ Additionally, abnormally high levels of IFN$\alpha$ are present in healthy first degree relatives of SLE patients as compared to healthy unrelated subjects. ${ }^{13}$ Thus whether interferon- $\alpha$ is a causal agent in SLE or a secondary reactive finding in such disease remains to be further studied.

The primary aim of this study was to evaluate levels of ghrelin and INF- $\alpha$ in SLE patients and their relation to different clinical manifestations of the disease. Moreover, to study their contribution to inflammatory process in patients with SLE via estimating their correlation with disease activity markers in such patients.

\section{SUBJECTS AND METHODS}

Fifty four SLE patients (Male/Female: 10/44, mean age was 21.2 \pm 11.1 years) (group I), were recruited in the study from patients attending Rheumatology and Immunology Unit in Mansoura University Hospital, from the period of November 2012 to March 2013. SLE patients were meeting the revised American College of Rheumatology (ACR) classification criteria for SLE. ${ }^{14}$ Forty six age and sex matched healthy subjects served as control group (group II). Activity of SLE was evaluated according to systemic lupus erythematosus Disease Activity Index (SLEDAI).

All patients were subjected to full history taking and thorough physical examination. Body mass index (BMI) was calculated for all participants. Full immunological laboratory testing was performed to all patients including: ESR, CRP, C3, C4, ANA, and anti-dsDNA.

Total fasting plasma ghrelin hormone was measured for all the studied groups using enzyme linked immune sorbent assay (ELISA) kit. ${ }^{15}$ Sun Red Human Ghrelin ELISA Kit, Catalogue No. 200-12-0973 was used in this study. Assay has a sensitivity of $0.6 \mathrm{pg} / \mathrm{ml}$.

Serum level of IFN- $\alpha$ was measured using an enzyme linked immunosorbent assay (ELISA) kit (Bender, Medsystems, Vienna, Austria), described a modified protocol to neutralize heterotrophile antibodies and avoid false-positive levels of IFN- $\alpha$ by adding $5 \%$ mouse serum to the assay buffer was used in the current assay. ${ }^{16}$

Inclusion criteria; all the studied patients fulfilled at least 4 of the 11 ACR classification criteria of systemic lupus erythematosus.

Exclusion criteria; patients with other autoimmune rheumatic diseases, type 1 diabetes mellitus, autoimmune thyroid disease, metabolic diseases, and pregnancy were excluded from the study. As INF- $\alpha$ has been implicated in the pathogenesis of these disorders to some degree.

Written informed consents were taken from all participants, and the study was approved by ethical committee of Mansoura Faculty of Medicine.
Immunosuppressive agents taken by enrolled patients were: hydroxychloroquine (dose $200 \mathrm{mg}$ /day), azathioprine (100-150 mg/day), cyclophosphamide (1000 $\mathrm{mg} / \mathrm{month}$ in pulse IV), and corticosteroids (dose from 10 to $40 \mathrm{mg} /$ day).

\section{RESULTS}

This is a case control study carried out on fifty four SLE patients, mean age $21.2 \pm 11.1$ years. In addition, 46 apparently healthy controls, mean age $22.9 \pm 12.1$ were included.

\section{Demographic and clinical data of the studied groups}

The frequencies of different clinical manifestations presented in the studied SLE patients are shown in Table (1). There was no significant difference between patients and controls as regards age, sex and height. While weight and BMI of SLE patients were significantly lower in comparison to controls. Diastolic and Systolic BP were significantly higher in SLE patients than controls (Table 1).

\section{Laboratory findings in the studied groups}

There were significantly lower hemoglobin, WBCs and platelet count in SLE patients in comparison to controls while ESR, CRP, anti-ds DNA and ANA serum levels were significantly higher in SLE patients than controls (Table 2). Serum LDL was the only significantly elevated in the lipid profile of the SLE patients in comparison to controls. INF- $\alpha$ and ghrelin hormone levels were highly significantly elevated in SLE patients in comparison to control group (Table 2, Figures 1 and 2).

Correlation between ghrelin hormone level and different study parameters

Ghrelin hormone in SLE patients was significantly negatively correlated with weight $(r=-0.3 \& \mathrm{p}=0.056)$, and HDL ( $\mathrm{r}=-0.3 \& \mathrm{p}=0.01$ ), while as it was positively correlated with LDL ( $\mathrm{r}=0.3 \& \mathrm{p}=0.03$ ) (Table 3 and figure 4). There was highly significant correlation between serum ghrelin levels and all activity markers of SLE, SLEDAI ( $\mathrm{r}=0.7 \& \mathrm{p}<0.0001)$, ANA $(\mathrm{r}=0.5 \&$ $\mathrm{p}<0.0001)$, and anti-ds DNA ( $\mathrm{r}=0.4 \& \mathrm{p}<0.002)$ (Table 3 ). Significant positive correlation of ghrelin and INF- $\alpha$ serum levels was also detected $(\mathrm{r}=0.3 \& \mathrm{p}<0.01)$ (Table 3 and Figure 3).

Ghrelin hormone levels in SLE patients according to the system affected

In the present study, we found that SLE patients with lupus nephritis have significantly increased ghrelin hormone levels than those patients without nephritis (466.4 \pm 205.4 , vs $360.3 \pm 130.8, \quad \mathrm{p}=0.004)$ (Table 4 and Figure 5). While there was no significant difference in ghrelin hormone levels in SLE patients with or without mucocutaneous manifestations, articular involvement, cerebritis, serositis, vasculitis or constitutional symptoms as shown in Table (4). 
Table 1. Demographic \& Clinical data of studied groups.

\begin{tabular}{lccc}
\hline & $\begin{array}{c}\text { SLE }(\mathbf{n}=\mathbf{5 4}) \\
\text { Mean } \pm \text { SD or \% }\end{array}$ & $\begin{array}{c}\text { Control } \\
(\mathbf{n = 4 6 )}\end{array}$ & P-value \\
\hline Age (ys) & $21.2 \pm 11.1$ & $22.9 \pm 12.1$ & NS \\
Female $\mathrm{n}(\%)$ & $44(81.5 \%)$ & $30(65 \%)$ & $\mathrm{NS}$ \\
Height (m) & $1.6 \pm 0.1$ & $1.62 \pm 0.1$ & $\mathrm{NS}$ \\
Weight (kg) & $70.8 \pm 11.2$ & $71.5 \pm 7.4$ & $0.02^{*}$ \\
BMI (kg/m2) & $25.7 \pm 1.3$ & $27.1 \pm 4.1$ & $0.03^{*}$ \\
Systolic BP (mmHg) & $129.1 \pm 16$ & $121.5 \pm 8$ & $0.004^{* *}$ \\
Diastolic BP (mmHg) & $84 \pm 12.4$ & $78.3 \pm 7$ & $0.007^{* *}$ \\
Clinical Manifestations: & & & - \\
Mucocutaneous & $44(81.5 \%)$ & - & - \\
Articular & $40(74.1 \%)$ & - & - \\
Nephritis & $35(64.8)$ & - & - \\
Constitutional & $14(25.9 \%)$ & - & - \\
Serositis & $10(18.5 \%)$ & - & - \\
Vasculitis & $8(14.8 \%)$ & - & - \\
Centeral nervous system & $6(11.1 \%)$ & - & - \\
SLEDAI & $15 \pm 8.4$ & - & - \\
\hline
\end{tabular}

Table 2. Laboratory characteristics of SLE patients.

\begin{tabular}{|c|c|c|c|}
\hline & SLE $(n=54)$ & Control $(n=46)$ & P-value \\
\hline Hemoglobin gm/dl & $11.3 \pm 1.9$ & $13.5 \pm 1.6$ & $<0.0001$ \\
\hline WBC $\left(10^{3}\right)$ & $4.7 \pm 1.6$ & $5.6 \pm 0.9$ & $<0.0001$ \\
\hline Platelets $\left(10^{3}\right)$ & $162 \pm 107$ & $377 \pm 118$ & $<0.0001$ \\
\hline $\mathrm{ESR} \mathrm{mm} / \mathrm{h}$ & $71.6 \pm 35$ & $12.9 \pm 2.6$ & $<0.0001$ \\
\hline CRP & $5.4 \pm 1.5$ & $4 \pm 0.4$ & $<0.0001$ \\
\hline ANA titer & $100.9 \pm 51.1$ & $5.8 \pm 4.9$ & $<0.0001$ \\
\hline Anti ds DNA & $124.5 \pm 49.3$ & $11.2 \pm 9.8$ & $<0.0001$ \\
\hline Cholesterol mg/dl & $125.4 \pm 75.6$ & $122.6 \pm 57.5$ & NS \\
\hline Triglycerides mg/dl & $129.4 \pm 57.9$ & $115.3 \pm 53.1$ & NS \\
\hline HDL mg/dl & $40.7 \pm 5.9$ & $41.6 \pm 7.2$ & NS \\
\hline LDL mg/dl & $179.2 \pm 66.1$ & $145.8 \pm 57.2$ & $<0.008$ \\
\hline $\mathrm{INF}-\alpha \mathrm{IU} / \mathrm{ml}$ & $84.1 \pm 56.5$ & $5.1 \pm 5.1$ & $<0.0001$ \\
\hline Ghrelin $\mathrm{pg} / \mathrm{ml}$ & $429.1 \pm 188.3$ & $139.1 \pm 62.3$ & $<0.0001$ \\
\hline
\end{tabular}

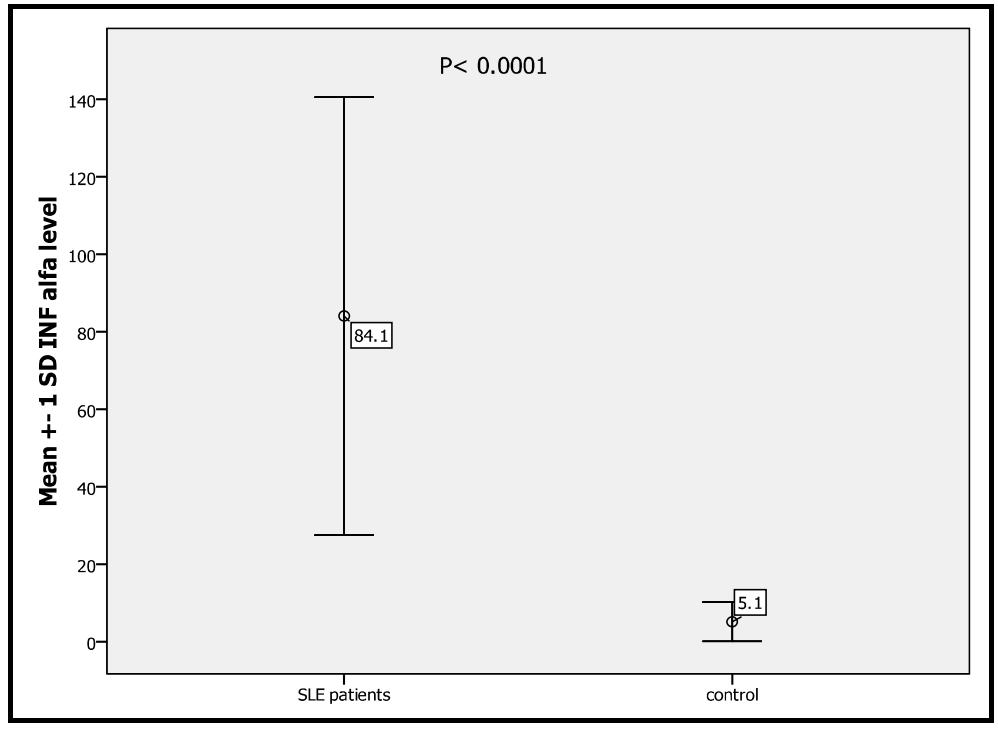

Figure 1. Comparison of serum INF- $\alpha$ levels in SLE patients and controls. 


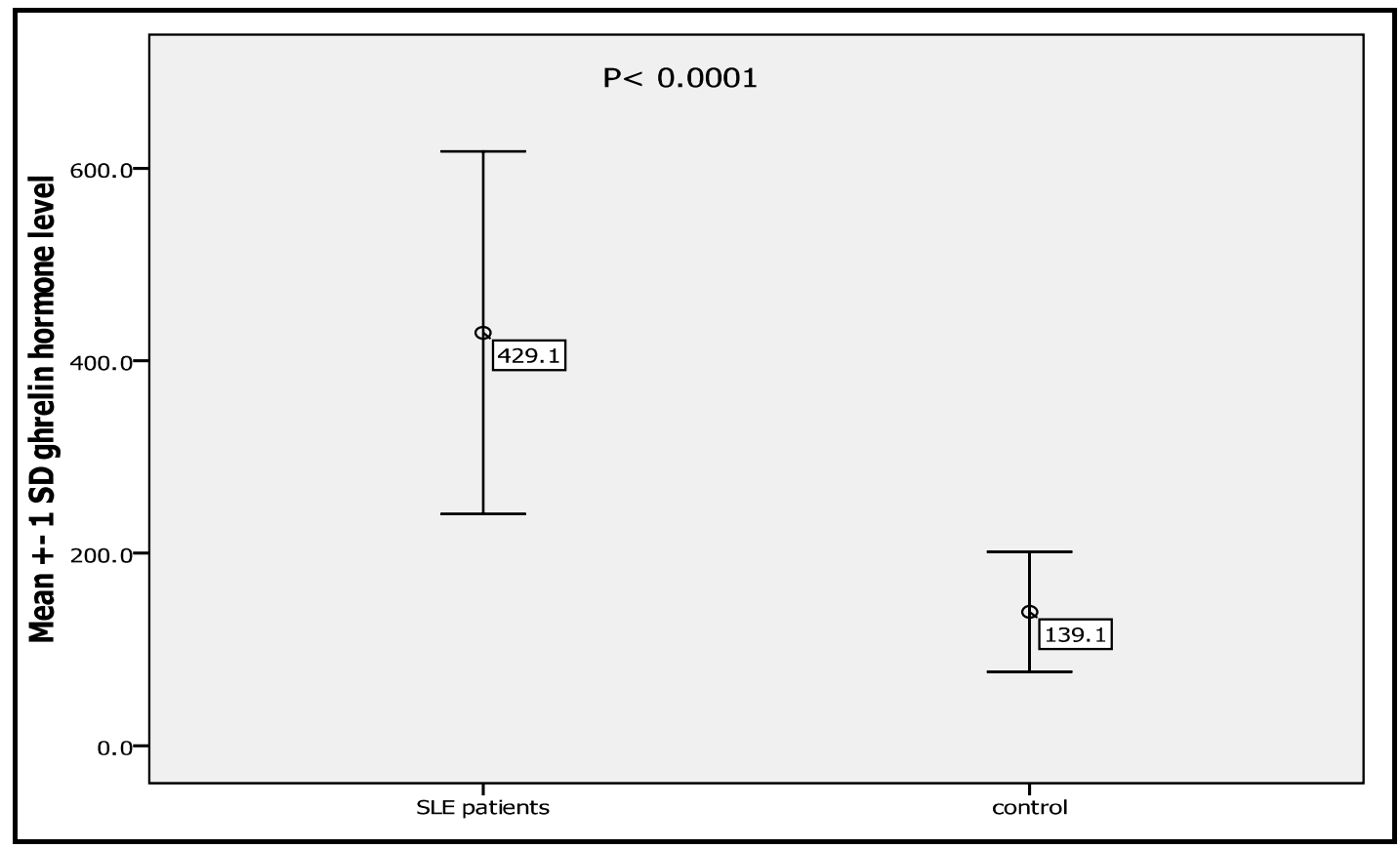

Figure 2. Comparison of serum Ghrelin levels in SLE patients and controls.

Table 3. Pearson's Correlation of Ghrelin hormone with clinical and laboratory parameters of studied groups.

\begin{tabular}{|c|c|c|c|c|}
\hline & \multicolumn{2}{|c|}{ SLE $(n=54)$} & \multicolumn{2}{|c|}{ Control $(n=40)$} \\
\hline & $\mathbf{r}$ & $\mathbf{p}$ & $\mathbf{r}$ & $\mathbf{p}$ \\
\hline Age & -0.01 & NS & 0.1 & NS \\
\hline Systolic blood pressure & -0.1 & NS & 0.2 & NS \\
\hline Diastolic blood pressure & -0.2 & NS & 0.02 & NS \\
\hline Height & -0.2 & NS & -0.2 & NS \\
\hline Weight & -0.3 & 0.056 & -0.1 & NS \\
\hline BMI & -0.2 & NS & 0.02 & NS \\
\hline Cholesterol & 0.1 & NS & 0.1 & NS \\
\hline Triglycerides & 0.03 & NS & 0.2 & NS \\
\hline HDL & -0.3 & 0.01 & -0.1 & NS \\
\hline LDL & 0.3 & 0.03 & -0.1 & NS \\
\hline ESR & -0.1 & NS & 0.1 & NS \\
\hline $\mathrm{Hb}$ & -0.04 & NS & -0.1 & NS \\
\hline WBCs & 0.3 & NS & -0.1 & NS \\
\hline Platelets & -0.1 & NS & 0.03 & Ns \\
\hline SLEDAI & 0.7 & $<0.0001$ & - & - \\
\hline ANA & 0.5 & $<0.0001$ & -0.1 & NS \\
\hline Anti ds DNA & 0.4 & 0.002 & 0.1 & NS \\
\hline $\mathrm{INF} \alpha$ & 0.3 & 0.01 & -0.2 & NS \\
\hline
\end{tabular}




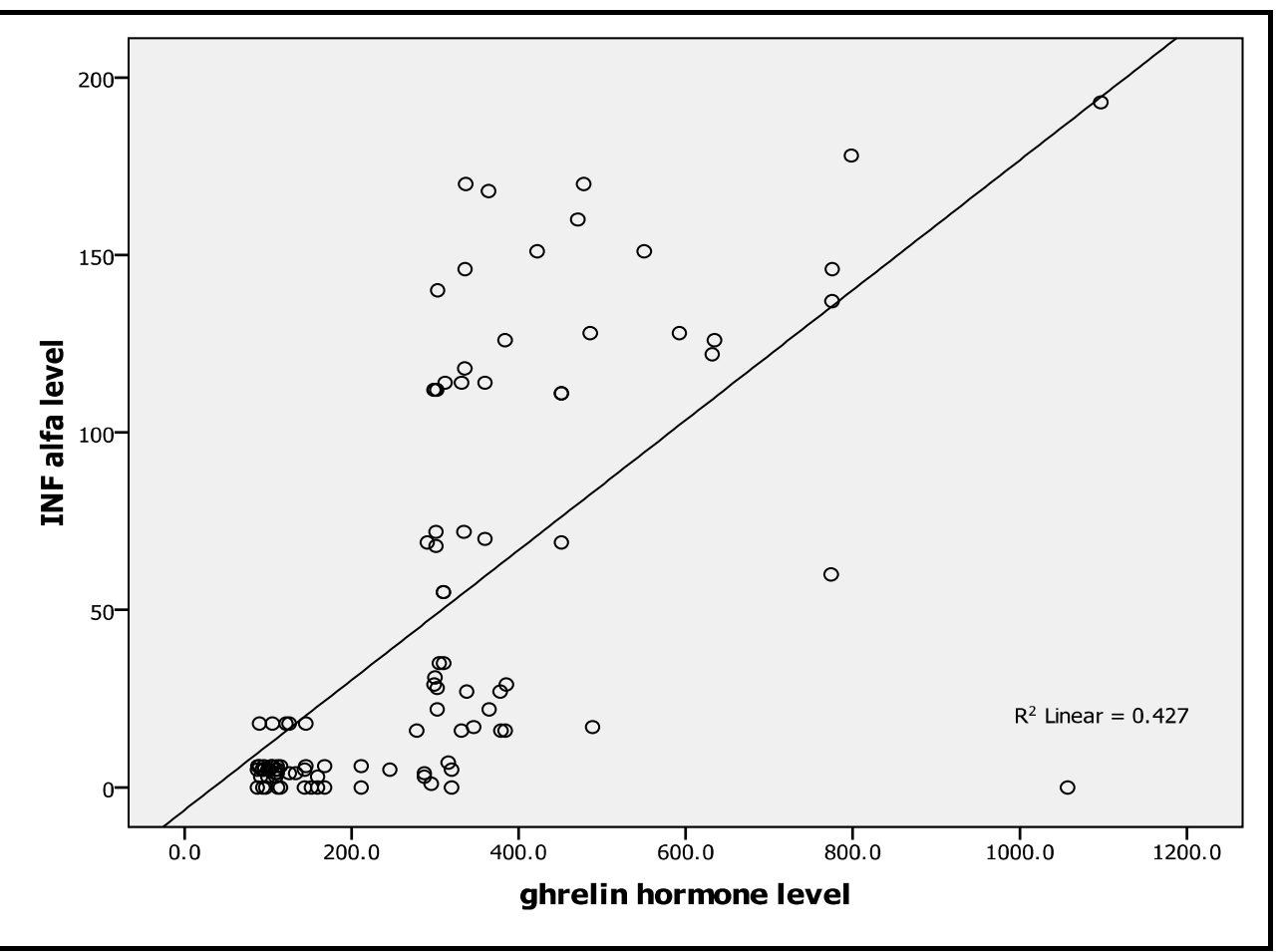

Figure 3. Correlation between ghrelin and INF- $\alpha$ serum levels in SLE patients.

Table 4. Ghrelin hormone level in SLE patients in different clinical presentation.

\begin{tabular}{|c|c|c|}
\hline & Ghrelin hormone (mean \pm SD) & P-value \\
\hline Mucocutaneous: no $(\mathrm{n}=10)$ & $499.3 \pm 249.8$ & \multirow[b]{2}{*}{ NS } \\
\hline yes $(n=44)$ & $413.1 \pm 171$ & \\
\hline Articular: no $(\mathrm{n}=14)$ & $413 \pm 181.8$ & \multirow{2}{*}{ NS } \\
\hline yes $(n=40)$ & $475 \pm 205.9$ & \\
\hline Nephritis: no $(\mathrm{n}=19)$ & $360.3 \pm 130.8$ & \multirow{2}{*}{$0.004 * *$} \\
\hline yes $(n=35)$ & $466.4 \pm 205.4$ & \\
\hline CNS: no $(n=48)$ & $437.2 \pm 197$ & \multirow{2}{*}{ NS } \\
\hline yes $(n=6)$ & $364.2 \pm 75.2$ & \\
\hline Serositis: no $(\mathrm{n}=44)$ & $436.4 \pm 174$ & \multirow{2}{*}{ NS } \\
\hline yes $(n=10)$ & $423.7 \pm 253.4$ & \\
\hline Vasculitis: no $(\mathrm{n}=46)$ & $417.8 \pm 164.7$ & \multirow{2}{*}{ NS } \\
\hline yes $(n=8)$ & $494.3 \pm 297.3$ & \\
\hline Constitutional symptoms: no $(n=40)$ & $411.9 \pm 171.4$ & \multirow{2}{*}{ NS } \\
\hline yes $(n=14)$ & $479.8 \pm 230$ & \\
\hline Haematologic: no $(n=34)$ & $436.2 \pm 183.6$ & \multirow{2}{*}{ NS } \\
\hline yes $(n=20)$ & $417.2 \pm 200.3$ & \\
\hline
\end{tabular}


Barakat, et al.: Role of Ghrelin Hormone in Systemic Lupus Erythematosus

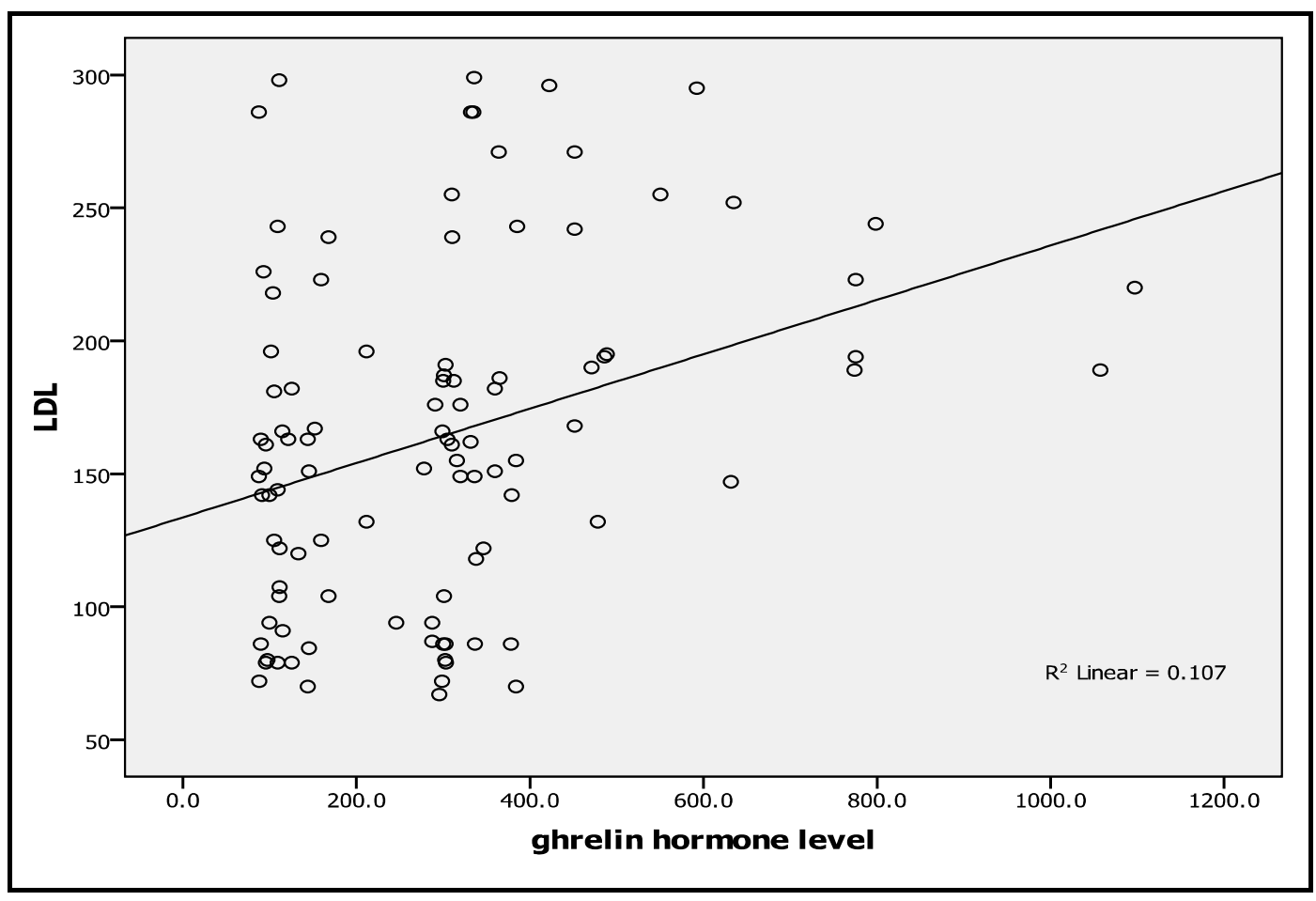

Figure 4. Correlation of ghrelin hormone with LDL level.

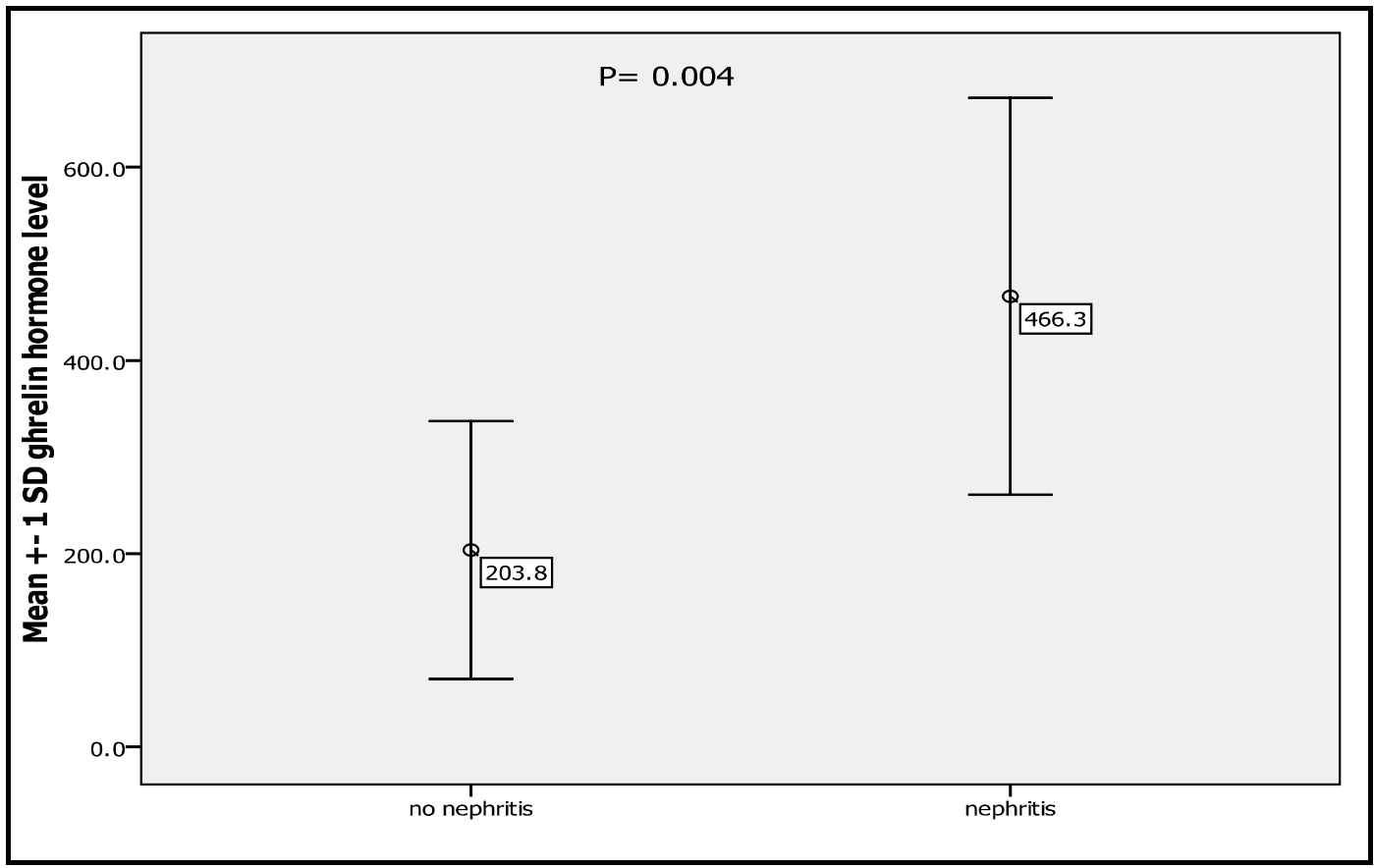

Figure 5. Comparison of ghrelin hormone level in SLE patients with and without nepritis. 


\section{DISCUSSION}

Systemic lupus erythematosus (SLE) is a severe multisystem autoimmune disease which is caused by a combination of genetic and environmental factors. ${ }^{17}$ Many lines of evidence underscore the importance of cytokines in SLE susceptibility. Circulating interferon alpha (IFN- $\alpha$ ) levels are high in many SLE patients. ${ }^{18,19}$ One of the most direct lines of evidence suggesting that high IFN- $\alpha$ is a primary pathogenic factor is that some individuals treated with recombinant interferon alpha (IFN- $\alpha$ ) for viral hepatitis develop de novo SLE, which typically resolves when IFN- $\alpha$ treatment is discontinued. ${ }^{11,12}$ It has not yet been clarified whether gherlin hormone level in SLE is related to the inflammatory environment of such disease. ${ }^{20}$

This case control study carried out on fifty four systemic lupus erythematosus patients recruited from patients attending Rheumatology and Immunology unit in Mansoura University Hospital, from the period of November 2012 to March 2013 in addition to forty age- and sex-matched healthy subjects served as control group.

In the present study we found that ghrelin hormone in SLE patients was significantly negatively correlated with weight of such patients, this could be explained by the role of ghrelin hormone in cachexia of chronic inflammatory diseases.

Systolic and diastolic BP were significantly higher in SLE patients compared to control group, these results were in agreement with Ryan ${ }^{21}$ and Bourre et al. ${ }^{22}$ who explained this by many mechanisms include the reninangiotensin system, endothelin, oxidative stress, sex steroids, metabolic changes, and most importantly, chronic inflammation and cytokines.

The presence of pancytopenia in SLE patients compared to control group in the present study were in agreement with many previous studies. ${ }^{14,23-26}$ This was explained by immune mediated bone marrow failure, excessive peripheral cells destruction or certain drugs and infections.

As regard lipid profile in SLE patients, serum LDL was significantly elevated in SLE patients when compared to controls. Moreover, ghrelin hormone in SLE patients was significantly negatively correlated with HDL but positively correlated with LDL. These results were in agreement with many authors who explained these findings by chronic inflammatory process in SLE patients as well as glucocorticoid therapy. ${ }^{27-29}$

As regards INF- $\alpha$ serum levels in the studied groups it was found to be significantly elevated in SLE patients in comparison to controls, which was in agreement with previous studies. ${ }^{17-19,30}$
Interestingly, the present study found significantly increased levels of ghrelin hormone among SLE patient with comparison to controls. These results were contrary to Kim et al. who found lower ghrelin hormone level in SLE patient. ${ }^{20}$ This controversy in results could be explained by different patient group selection in both studies. As in the present study the SLE patients were active and severe cases in comparison to Kim et al, as measured by SLEDAI and other disease activity markers such as anti-ds DNA and ANA titers, as well as indicators of severity of disease as pancytopenia, nephritis, cerebritis and serositis, which consisted a significant part of our SLE patients presentations.

Moreover, a significant positive correlation was detected between ghrelin hormone and IFN- $\alpha$ level in the studied SLE patients. As well as, a positive significant correlation was found between ghrelin levels and markers of lupus activity including ANA, anti-ds DNA and SLEDAI. A significant positive correlation was also found between ghrelin hormone level and lupus nephritis. These data suggest that possible role for ghrelin hormone in the pathogenesis, clinical manifestations and activity of SLE, especially its possible significant role in patients with lupus nephritis.

\section{Conclusion}

These interesting results could illustrate both the role and synchronization between both ghrelin and INF- $\alpha$ in pathogenesis, activity of the disease, and more importantly in severity of SLE as nephritis and CNS lupus. Further longitudinal studies are required to evaluate the role of both biomarkers in the new strategies of treatment in SLE and the role that ghrelin plays in the assessment of disease activity of SLE.

[Disclosure: Authors report no conflict of interest]

\section{REFERENCES}

1. Rahman A, Isenberg DA: Systemic lupus erythematosus. N Engl J Med 2008; 358(9):929-939.

2. Kojima M, Hosoda H, Date Y, et al. "Ghrelin is a growth-hormone-releasing acylated peptide from stomach," Nature 1999; 402, no. 6762, pp. 656-660.

3. Howard AD, Feighner SD, Cully DF, et al. A receptor in pituitary and hypothalamus that functions in growth hormone release," Science 1996; 273( 5277) : 974-977.

4. Roux CW, Patterson M, Vincent RP, et al. Postprandial Plasma Ghrelin Is Suppressed Proportional to Meal Calorie Content in NormalWeight But Not Obese Subjects. Journal of Clinical Endocrinology and Metabolism 2005; 90(2): 10681071. 
5. Ariyasu H, Takaya K, Tagami T, et al. Stomach is a major source of circulating ghrelin, and feeding state determines plasma ghrelin-like immunoreactivity levels in humans," Journal of Clinical Endocrinology and Metabolism 2001; 86(10): 4753-4758.

6. Gnanapavan S, Kola B, Bustin SA, et al. The tissue distribution of the mRNA of ghrelin and subtypes of its receptor, GHS-R, in humans. Journal of Clinical Endocrinology and Metabolism 2002; 87(6): 2988-2991.

7. Al M, Ng L, Tyrrell P, et al. Adipokines as novel biomarkers in paediatric systemic lupus erythematosus. Rheumatology (Oxford). 2009; 48: 497-501.

8. Leite-Moreira AF and Soares JB. Physiological, pathological and potential therapeutic roles of ghrelin. Drug Discov Today. 2007;12:276-88.

9. Mak RH, Cheung WW, Zhan JY, et al. Cachexia and protein-energy wasting in children with chronic kidney disease. Pediatr Nephrol. 2012;27:173-181.

10. Pestka S, Krause CD and Walter MR. Interferonlike cytokines, and their receptors. Immunol Rev. 2004; 202:8-32.

11. Niewold TB. Interferon alpha-induced lupus: proof of principle. Journal of Clinical Rheumatology. 2008; 14( 3): 131-132,.

12. Niewold TB and Swedler WI. Systemic lupus erythematosus arising during interferon-alpha therapy for cryoglobulinemic vasculitis associated with hepatitis C. Clinical Rheumatology. 2005; 24(2): 178-181.

13. Shahin , Ahmed M. El-Refaey , Amany K. ElHawary, et al. Serum interferon-alpha level in first degree relatives of systemic lupus erythematosus patients: Correlation with autoantibodies titers The Egyptian Journal of Medical Human Genetics. 2011; 12: 139-146.

14. Tan EM, Cohen AS, Fries JF, et al. The 1982 revised criteria for the classification of systemic lupus erythematosus. Arthritis Rheum 1982;25:1271---7. and Hochberg MC. Updating the American College of Rheumatology revised criteria for the classification of systemic lupus erythematosus [letter]. Arthritis Rheum 1997; 40:1725.

15. García- M T , Fernández-S R, Domínguez-D A, et al. Fasting Plasma Ghrelin Levels Increase Progressively after Biliopancreatic Diversion: Oneyear Follow-upObesity Surgery, 2005; 15(2): 187 190.

16. Aly T, Devendra D, Barker J, et al. Heterophile antibodies masquerade as interferon-a in subjects with new-onset type 1 diabetes. Diabetes Care. 2004; 27: 1205-6.

17. Harley JB, Kelly JA, and Kaufman K M. Unraveling the genetics of systemic lupus erythematosus. Springer Seminars in Immunopathology. 2006; 28(2): 119-130.

18. Weckerle, CE, Franek, BS, Kelly, JA, et al. Network analysis of associations between serum interferon- $\alpha$ activity, autoantibodies, and clinical features in systemic lupus erythematosus. Arthritis and Rheumatism. 2011; 63(4): 1044-1053.

19. Ko K, Franek BS, Marion M, et al. Genetic ancestry, serum interferon-alpha activity, and autoantibodies in systemic lupus erythematosus. The Journal of Rheumatology. 2012, 39(6):12381240.

20. Kim HA, Choi GS, Jeon JY, et al. Leptin and ghrelin in Korean systemic lupus erythematosus. Lupus. 2010; 19(2): 170-4.

21. Ryan MJ. The pathophysiology of hypertension in systemic lupus erythematosus Am J Physiol Regul Integr Comp Physiol. 2009; 296(4).

22. Bourre'-Tessier J, Huynh T, Clarke AE, et al.Features associated with cardiac abnormalities in systemic lupus erythematosus Lupus. 2011, 20: $1518-1525$.

23. Hochberg MC. Updating the American College of Rheumatology revised criteria the classification of systemic lupus erythematosus. Arthritis Rheum. 1997; 40(9): 1725.

24. Ronnblom L. Potential role of IFNa in adult lupus. Arthritis Res Ther. 2010; 12(Suppl. 1): S3.

25. Schur PH and Berliner N. Hematological manifestations of systemic lupus erythematosus in adults. Up To Date, 2012.

26. Broder A and Putterman C. Hydroxychloroquine use is associated with lower odds of persistently positive antiphospholipid antibodies and/or lupus anticoagulant in systemic lupus erythematosus. J Rheumatol. 2013; 40(1): 30-33.

27. Gustafsson J, Gunnarsson I, Bo" rjesson O, et al. Predictors of the first cardiovascular event in patients with systemic lupus erythematosus a prospective cohort study. Arthritis Res Ther. 2009; 11(6): 186.

28. Bengtsson $\mathrm{C}$, Ohman ML, Nived O, et al. Cardiovascular event in systemic lupus erythematosus in Northern Sweden: incidence and predictors in a 7-year follow-up study. Lupus. 2012; 21(4):452-9.

29. Khaled MSO and Naglaa YA. Early detection of premature subclinical coronary atherosclerosis in systemic lupus erythematosus patients The Egyptian Heart Journal. 2013; 65:281-288s.

30. Mangale D, Kariuki SN. Chrabot BS, et al. Familial Aggregation of High Tumor Necrosis Factor Alpha Levels in Systemic Lupus Erythematosus. Clinical and Developmental Immunology. 2013; Accepted 19 August 2013, Article ID, 267430, 6 pages. 